\title{
Encouraging Positive Youth Video Game Activities ${ }^{1}$
}

\section{Rosemary V. Barnett ${ }^{2}$}

In todays world youth are increasingly using electronic media. School assignments include web-based research for homework, e-mail has replaced letter writing, and the convenience of instant messaging is starting to replace the telephone. Youth today are more media literate than their parents, yet the outcomes of this transition are not always positive. Youth recreation has merged with media to include video games, music downloading, and interactive websites, in many cases replacing traditional youth activities, such as basketball, swimming, or other outdoor recreation.

\section{Video game violence and levels of developmental appropriateness}

Leisure activities in the form of electronic video games for youth have gradually become more popular since they were first introduced during the 1970s. Recent studies on children's activities have found gender differences in time commitment to electronic games as early as age 3 (Huston, Wright, Marquis \& Green, 1999). In a study where parents were interviewed to describe their child's activities in the previous 24-hour period, it was found that girls rarely played electronic games, however, boys played 10 minutes on weekends. By age 6 , girls played 15 minutes and boys typically played 40 minutes. A
Kaiser Foundation study of 3,000 children ages 2-18 similarly found that $55 \%$ of boys and $23 \%$ of girls reported playing console-based electronic games daily (Roberts, Foehr, et al., 1999), indicating the popularity of this activity in this national sample. Further, a time study found peaks in playing time from middle childhood to adolescence (Buchman \& Funk, 1996) with $4^{\text {th }}$ grade girls playing 4.5 hours in a typical week as compared to $4^{\text {th }}$ grade boys playing 7 hours weekly on average; $8^{\text {th }}$ grade girls playing two hours as compared to $8^{\text {th }}$ grade boys playing less than 4 hours.

These and other studies have provided research that indicates that most children under high school age are devoting time to playing electronic games and across all ages, boys play for more time than girls. In about $5 \%$ of the players, there is evidence that their time commitment to playing is so excessive that it may be interfering with other activities. Girls have been found to prefer cartoon or fantasy violence and this preference increases from late elementary to middle school while their general entertainment preference increases from Grade 4-7 and their educational preference decreases from Grade 5-8. Boys have been found to prefer more realistic, human violent games and their preference for fantasy violence decreases from late elementary to middle

1. This document is FCS2238, one of a series of the Family, Youth and Community Sciences Department, Florida Cooperative Extension Service, Institute of Food and Agricultural Sciences, University of Florida. Original publication date: December 2005. Visit the EDIS Web Site at http://edis.ifas.ufl.edu

2. Rosemary V. Barnett, Ph.D., assistant professor, Department of Family, Youth and Community Sciences, Florida Cooperative Extension Service, Institute of Food and Agricultural Sciences, University of Florida, Gainesville FL 32611.

The Institute of Food and Agricultural Sciences (IFAS) is an Equal Opportunity Institution authorized to provide research, educational information and other services only to individuals and institutions that function with non-discrimination with respect to race, creed, color, religion, age, disability, sex, sexual orientation, marital status, national origin, political opinions or affiliations. U.S. Department of Agriculture, Cooperative Extension Service, University of Florida, IFAS, Florida A. \& M. University Cooperative Extension Program, and Boards of County Commissioners Cooperating. Larry Arrington, Dean 
school while their educational game preference decreases from Grades 5-7. Research has found that in general among most youth, there is no significant impairment in psychological functioning caused by game playing, however, some children have a special vulnerability. These "high risk players" are defined as those vulnerable children in whom, even a small increase in exposure to aggressive behavior, may trigger aggression (Funk, Buchman \& Germann, 2000).

In recent field observations at a mall video arcade, Barnett et al. (2005) found that youth, primarily young boys (about 7-10 years old), were dropped off by parents and left unattended. Older adolescents tended to play the same game for longer time durations, while younger children moved to other games. Attire seemed to relate to game preference. Boys in sports attire migrated to sports-oriented games while youth attired in black played games more violent in nature. Shooting games were very highly frequented and comprised nearly one half of the working machines in the arcade. There were 11 labeled with the Animated Violence rating, 9 labeled with the Human Violence rating, and even some labeled with the Mild - Strong rating. Games ranged in cost from .50 to $\$ 1.00$ for a play-time ranging from 2-3 minutes to 5 minutes on average, not including extended round features.

An interesting observation was related to the game nature. Games had elements such as Asian fighting, guns with silent telescope features; games that allowed the player to change weapons from Revolver to Shotgun to Machine Gun to Grenade; games with lifelike violence that focused on shooting humans that bled when hit to more graphic depictions of shooting ghouls upon which blood gushed similar to that of a cut artery. Some games featured animated dancing girls in bikinis; one required the player to keep bikini-clad girls in sight to increase their "life gauge"; another featured a female figure with metal breast covers; all depicted an element of sexuality by portraying females with large-chests, thin-frames, and scantily-clad attire.

The most notable observation was that there was very little monitoring by adults of play time or play selections made by the children at the arcade. The games were taking on the role of guardian or super-peer, occupying their activity time and entertaining them while their parents ran errands. The arcade employee did not engage in conversation with anyone in the arcade nor monitor the selections, even though some were rated "Animated Violence Strong." The level of violence was obviously inappropriate for viewing by the age groups playing the games.

\section{What this means to parents}

Research in this area is new and much is still needed before we know all of the effects of media on children. There is evidence, however, that some games are not appropriate for youth. Youth are able to gain ready access to games, and media use is occupying more time by youth than ever before. Instead of totally restricting media use for recreation, parents may need to explore gaming more than before due to its increasing popularity and wide acceptance. By becoming more informed, they may guide their children to better choices.

\section{Implications for youth, parents, and agents}

- Inform parents of the nature of some games so they may help youth make appropriate game selections for their developmental level.

- Encourage parents to test games prior to allowing their child to play them to make sure that they are not too violent in nature or contain figures with inappropriate sexual connotations.

- Parents may also be encouraged to play games with their children to keep informed of the latest changes and current trends in popular games.

- Alert parents to the possibility of youth being able to play such games if left unattended or unmonitored as well as to the dangers of leaving their child alone.

- Youth must also be educated about the rating systems on games so that they may make selections that are correct for their age. 
- Encourage youth to limit their playing time so that the screen does not become their sole source of entertainment.

- Provide a wide variety of physical activities for youth that will offset screen-time, such as outdoor sports, crafts, or bicycling. These will keep youth grounded in the real world and provide quality time for all.

\section{References}

Barnett, R., Hirsch, J. \& Ferguson, K. \& Hicks, D. (2005). Saturdays at the mall arcade: Observations of unsupervised youths time commitment and selection of video games (In progress).

Buchman, D.D. \& Funk, J.B. (1996). Video and computer games in the 90s: Children's time commitment and game preference. Children Today, $24,12-15,31$.

Funk, J.B., Buchman, D.D., \& Germann, J.N. (2000). Preference for violent electronic games, self-concept and gender differences in young children. American Journal of Orthopsychiatrty, 70, 233-241.

Huston, A.C., Wright, J.C., Marquis, J., \& Green, S.B. (1999) How young children spend their time: Television and other activities. Developmental Psychology, 35, 912-925.

Roberts, D.F., Foehr, U.G., Rideout, V.J., \& Brodie, M. (1999). Kids and media at the new millennium: A Kaiser Family Foundation Report. Menlo Park, CA: Henry J. Kaiser Family Foundation. 